\title{
Effects of berberine and red yeast on proinflammatory cytokines IL-6 and TNF- $\alpha$ in peripheral blood mononuclear cells (PBMCs) of human subjects
}

\section{Carmen Spatuzza ${ }^{1+}$, Loredana Postiglione ${ }^{2+}$, Bianca Covelli $^{2}$, Margherita Ricciardone $^{2}$, Claudio Benvenuti ${ }^{3}$, Paolo Mondola ${ }^{1}$ and Anna Belfiore ${ }^{1 *}$}

1 Unità di Fisiologia, Dipartimento di Medicina Clinica e Chirurgia, University "Federico II," Naples, Italy

2 Unità di Patologia Clinica, Dipartimento di Scienze Mediche Traslazionali, University "Federico II," Naples, Italy

${ }^{3}$ Dipartimento Medico, Rottapharm Madaus, Monza, Italy

\section{Edited by:}

Ditte Lundvig, Radboud University

Medical Center, Netherlands

Reviewed by:

Bernhard H. Rauch, University

Medicine Greifswald, Germany

Francesca Oliviero, University of

Padova, Italy

*Correspondence:

Anna Belfiore, University of Naples

"Federico II", via S. Pansini 5, 80131

Naples, Italy

e-mail: abelfior@unina.it

${ }^{t}$ These authors have contributed equally to this work
Background and Aims: Obesity is a condition associated with chronic or acute inflammatory response characterized by an increase of proinflammatory cytokine levels. Peripheral blood mononuclear cells (PBMCs) migrate in adipose tissue inducing synthesis and secretion of adipocytokines as IL-6 and TNF- $\alpha$. The aim of this study was to investigate the effect of berberine (a natural alkaloid) and red yeast (a natural antioxidant) on IL-6 and TNF- $\alpha$ cytokines release and gene expression, in circulating lipopolisaccarides (LPS) stimulated PBMCs.

Methods and Results: PBMCs isolated from whole blood of healthy donors were stimulated with LPS to induce cytokines production; simultaneously cells were treated with increasing doses of berberine and red yeast. The substances were administered alone or in association. IL-6 and TNF- $\alpha$ protein levels in the culture medium and their mRNA levels were assessed by ELISA and real time PCR, respectively. Berberine and red yeast treatment prevented the LPS induction of IL-6 release in the culture medium of PBMCs. In addition, berberine plus red yeast treatment showed a synergic inhibitory effect on IL-6 release at low concentration. Berberine and red yeast showed an inhibitory effect also on LPS induction of TNF- $\alpha$ release exerting a synergic effect mainly at high concentrations. On the contrary, berberine and red yeast did not significantly affect IL-6 and TNF- $\alpha$ mRNA levels induced by LPS. In this case, only concomitant treatment of PBMCs with high doses of berberine and red yeast inhibits LPS induced IL-6 or TNF- $\alpha$ mRNA levels.

Conclusions: The results of our study show that both berberine and red yeast were able to carry out anti-inflammatory action through an inhibition of proinflammatory IL-6 and TNF- $\alpha$ protein release. Moreover, when given in combination these substances were able to inhibit IL-6 and TNF- $\alpha$ gene expression in PBMCs activated by LPS. Therefore, these substances could represent a useful pharmacological treatment to reduce the proinflammatory status accompanied with obesity.

Keywords: interleukin 6, tumor necrosis factor $\alpha$, berberine, red yeast, obesity, inflammation

\section{INTRODUCTION}

Many data indicate that obesity is associated with either a chronic or an acute inflammatory response characterized by an increase of cytokine production (Bastard et al., 2006). Recent data show that circulating mononuclear cells are involved in these increased proinflammatory proteins production in obese subjects. This effect seems to be mediated by the migration of mononuclear cells (MNCs) to arterial wall as well as into adipocyte tissue (Weisberg et al., 2003), in this tissue, MNCs induce adipocytokines such as interleukin 6 (IL-6) and tumor necrosis factor $\alpha$ (TNF- $\alpha$ ) (Solá et al., 2009).

Some studies indicate that monocytes and macrophages are strongly increased in the adipose tissue of obese subjects where they produce proinflammatory cytokines that further increase the secretion of adipocyte proinflammatory proteins (adipokines) (Ghanim et al., 2004).

Berberine is an alkaloid extracted from plants belonging to Berberidaceae family that possesses many biological and pharmacological effects, such as inhibition of adipogenesis, antiinflammatory activity, reduced insulin resistance, and potential immunomodulatory properties (Choi et al., 2006; Lee et al., 2006; Yi et al., 2008).

Red Yeast is the product of Monascus purpureus micetes rice fermentation showing strong antioxidant properties. Monacolin $\mathrm{K}$, one of the red yeast metabolically active compounds, is a 3-hydroxy-3-methylglutaryl-coenzyme A reductase inhibitor 
effective in reducing the cholesterol synthesis (Lin et al., 2008a). This is a statin-like effect.

Even if several molecular mechanisms involved in the pathogenesis of chronic inflammation in obesity take place into adipose tissue, many studies demonstrate a MNCs involvement in generating proinflammatory cytokines overexpression in obese subjects (Ghanim et al., 2004). It is known that MNCs are able either to migrate through blood vessels in order to generate foam cells, contributing to atherosclerosis plaques formation, or to migrate in adipose tissue to produce proinflammatory cytokines like TNF$\alpha$ and IL-6 (Weisberg et al., 2003). It is also well known that lipopolisaccarides (LPS) are recognized by TR4 membrane receptor mainly localized on monocytes/ macrophages membrane surface; the TR4 receptor activation carries out the production of many proinflammatory cytokines. Therefore, LPS stimulating MNCs may provide a representative model of the overall inflammatory status of body as well as of adipose tissue.

This study was aimed to investigate the effect of berberine and red yeast on proinflammatory cytokines, IL- 6 and TNF- $\alpha$ protein release, and their expression in LPS stimulated PBMCs from donors buffy coats. Moreover, this study would further evaluate whether there is a synergism of these molecules in reducing proinflammatory cytokine levels.

\section{MATERIALS AND METHODS PBMCS EXTRACTION AND STIMULATION}

PBMCs were isolated from healthy donor buffy coats using Ficoll Paque gradient (GE Healthcare Europe, Munich, Germany). All samples were obtained in accordance with the requirements of the hospital ethics committee. The investigation conformed to the principles outlined in the Declaration of Helsinki (Rickham, 1966).

Briefly, donor blood was diluted 1:10 in PBS $1 \mathrm{X}$ and stratified on Ficoll solution with a $3: 1 \mathrm{v} / \mathrm{v}$ ratio. After a $30 \mathrm{~min}$ centrifugation at 2200 r.p.m., PBMCs were recovered and resuspended in RPMI-1640 medium supplemented with 10\% FCS. $125000 / \mathrm{mL}$ PBMCs were cultured at $37^{\circ} \mathrm{C}$ in an humidified atmosphere with $5 \% \mathrm{CO}_{2}$. MNCs were stimulated with $50 \mathrm{ng} / \mathrm{mL}$ LPS (E. Coli Lipopolisaccarides-Sigma-Aldrich, St. Louis, MO) to induce cytokines production. Simultaneously, cells were treated with increasing doses $(1,10$ and $50 \mu \mathrm{g} / \mathrm{mL})$ of Berberine and red yeast containing $1.5 \%$ S.C. (Specific Concentration) of the metabolic active compound Monacolin K, singularly or in association for 3, 6 or $24 \mathrm{~h}$. Red yeast was kindly gifted by Rottapharm Spa. After incubation cells were recovered with cultured medium and centrifugated for $5 \mathrm{~min}$ at $2000 \mathrm{rpm}$. Supernatants containing secreted cytokines were collected.

\section{ELISA ASSAY}

TNF- $\alpha$ and IL- 6 concentrations in diluted (1:100) culture supernatants were measured by enzyme linked immunosorbent assay (ELISA) according to instruction of the manufacturer (R\&D Systems ELISA kit Minneapolis MN 55413, USA).

\section{RNA EXTRACTION}

After PBMCs stimulation, cells were collected and total RNA was extracted by using the TRIzol reagent (Invitrogen, Karlsruhe,
Germany). Extracted total RNA was quantified and the ratio A 260/280 was measured to verify its purity.

\section{REAL TIME PCR}

$0.5 \mu \mathrm{g}$ of total RNA were reverse-transcribed (Invitrogen Life Technologies Ltd, Paisley, UK) and real time RT-PCR was performed using iCycler Apparatus (Bio-Rad, CA). Forty PCR amplification cycles of $60 \mathrm{~s}\left(15 \mathrm{~s}, 95^{\circ} \mathrm{C} ; 45 \mathrm{~s}, 60^{\circ} \mathrm{C}\right)$ were run and amplification rates were monitored by the Sybr Green method. For PCR amplification the following primers were used: GAPDHf: GAA GGT GAA GGT CGG AGT C, GAPDHr: GAA GAT GGT GAT GGG ATT TC, TNF- $\alpha$ : AAG AGT TCC CCA GGG ACC TCT, TNF- $\alpha$ r: CCT GGG AGT AGA TGA GGT ACA, IL-6f: GGA CGG CTT TTA CTT AAA CGC CAA GG, IL-6r: ATC TTC CCT AGT TAC CCA GGT TCA GC.

\section{CELL VIABILITY ANALYSIS}

The cell viability, performed by Trypan blue test (Doyle and Griffiths, 1998), was higher than $90 \%$ in all the experimental conditions.

\section{STATISTICAL ANALYSIS}

Results were expressed as mean $\pm S D$.

Kruskall-Wallis non parametric analysis of Variance followed by Mann-Whitney $U$ test were used to compare the results.

\section{RESULTS \\ BERBERINE AND RED YEAST (1.5\% S.C. MONACOLIN K) REDUCE PROINFLAMMATORY IL- 6 AND TNF- $\alpha$ CYTOKINES SECRETION IN LPS ACTIVATED PBMCs}

LPS treatment of PBMCs induced the secretion of proinflammatory IL- 6 and TNF- $\alpha$ proteins. Berberine treatment reduced LPS inflammatory response by decreasing IL-6 release (Figure 1). The anti-inflammatory effect was significant at 3 and $24 \mathrm{~h}(p<0.05)$ (Figures 1A,C). Equally, red yeast reduced inflammatory response lowering IL-6 release in LPS activated PBMCs (Figure 1). We observed an inhibition of IL-6 secretion after $3 \mathrm{~h}$ and $6 \mathrm{~h}$ of treatment with 10 and $50 \mu \mathrm{g} / \mathrm{mL}$ red yeast compared to LPS treated cells $(p<0.05)$ (Figures 1A,B). After $24 \mathrm{~h}$ of incubation, red yeast significantly decreased IL6 release at all the doses used $(p<0.05)$ (Figure 1C). We observed that IL- 6 secretion inhibition in berberine plus red yeast stimulated PBMCs cells was more evident at low concentration $(1 \mu \mathrm{g} / \mathrm{mL})$ and at short time $(3 \mathrm{~h})(65.2 \%)(p$ $<0.05)$. In the same conditions, berberine or red yeast alone inhibited IL-6 secretion by $33 \%$ and $3 \%$, respectively (Figures 1A-C).

Berberine plus red yeast treatment carried out a synergic inhibitory effect on TNF- $\alpha$ secretion at all the incubation times; this effect was dose-dependent (Figures $2 \mathrm{~A}-\mathrm{C}$ ). After $3 \mathrm{~h}$ of treatment the inhibition was equal to $61.5 \%$ with the concentration of $50 \mu \mathrm{g} / \mathrm{mL}(p<0.05)$. After $6 \mathrm{~h}$ of incubation the synergic inhibitory effect was evident at 10 and $50 \mu \mathrm{g} / \mathrm{mL}(p<0.05)$ (Figure 2B), while TNF- $\alpha$ release was maximally inhibited by $64.7 \%$ after $24 \mathrm{~h}$ at $50 \mu \mathrm{g} / \mathrm{mL}$ of berberine plus red yeast treatment, compared to LPS treatment $(p<0.05)$ (Figure 2C). 


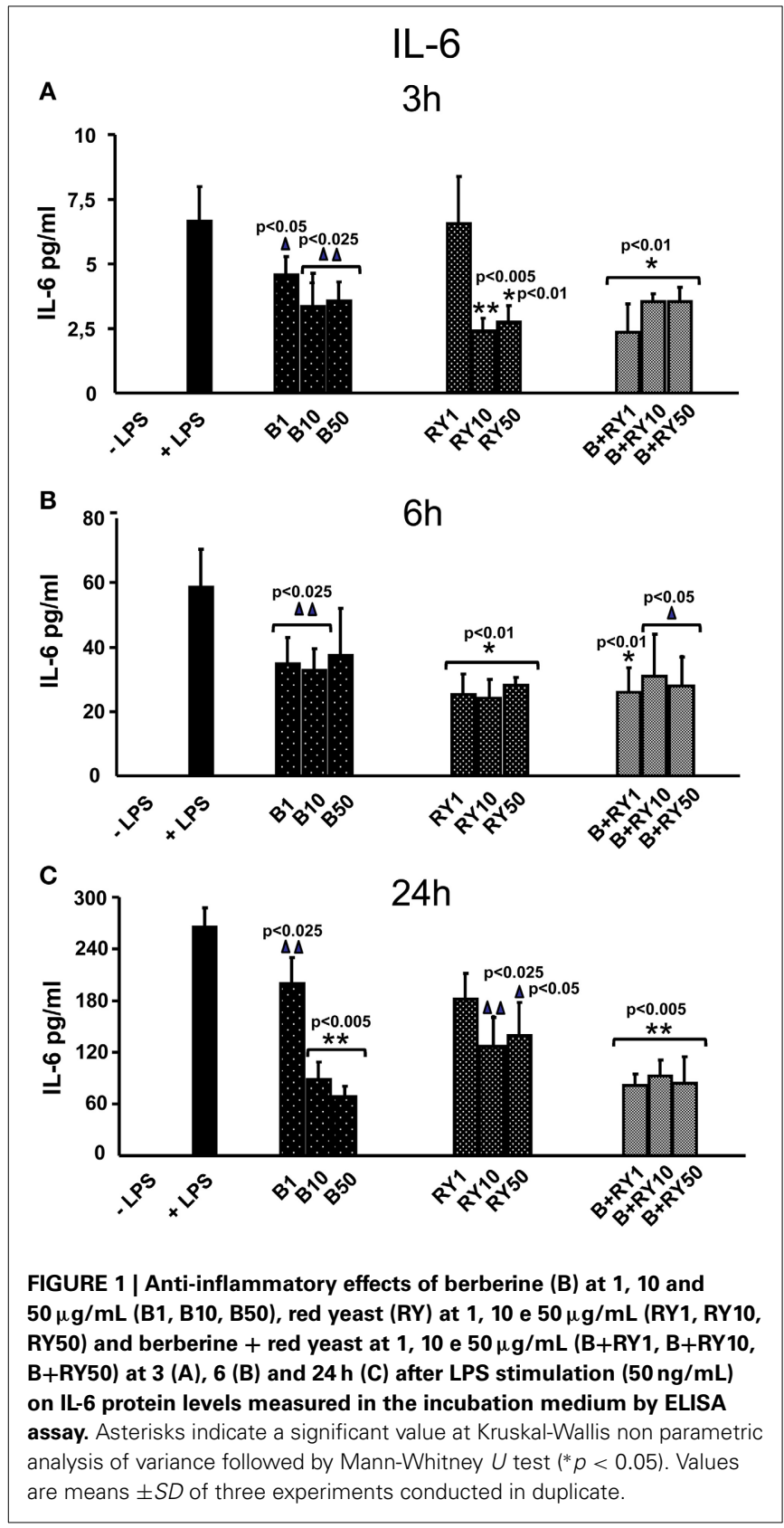

BERBERINE AND RED YEAST (1.5\% S.C. MONACOLIN K) REDUCE IL-6 AND TNF- $\alpha$ mRNA LEVELS IN LPS ACTIVATED PBMCs

Experiments of real time PCR were carried out starting from RNA of PBMCs stimulated with LPS. LPS treatment on PBMCs caused the induction of IL- 6 and TNF- $\alpha$ mRNA levels.

Berberine determined a slight reduction of LPS induced IL- 6 mRNA levels at 3, 6 and $24 \mathrm{~h}$, that was not statistically significative (Figures 3A-C). At the same time, red yeast had not a significant inhibitory effect on IL-6 mRNA levels (Figures 3A-C). Differently, concomitant treatment with $50 \mu \mathrm{g} / \mathrm{mL}$, of berberine and red yeast inhibited LPS induced IL-6 mRNA levels at 3, 6 and $24 \mathrm{~h}(p<0.05)$ of treatment (Figures 3A-C). In addition, TNF$\alpha$ inhibition was statistically significant with berberine and red

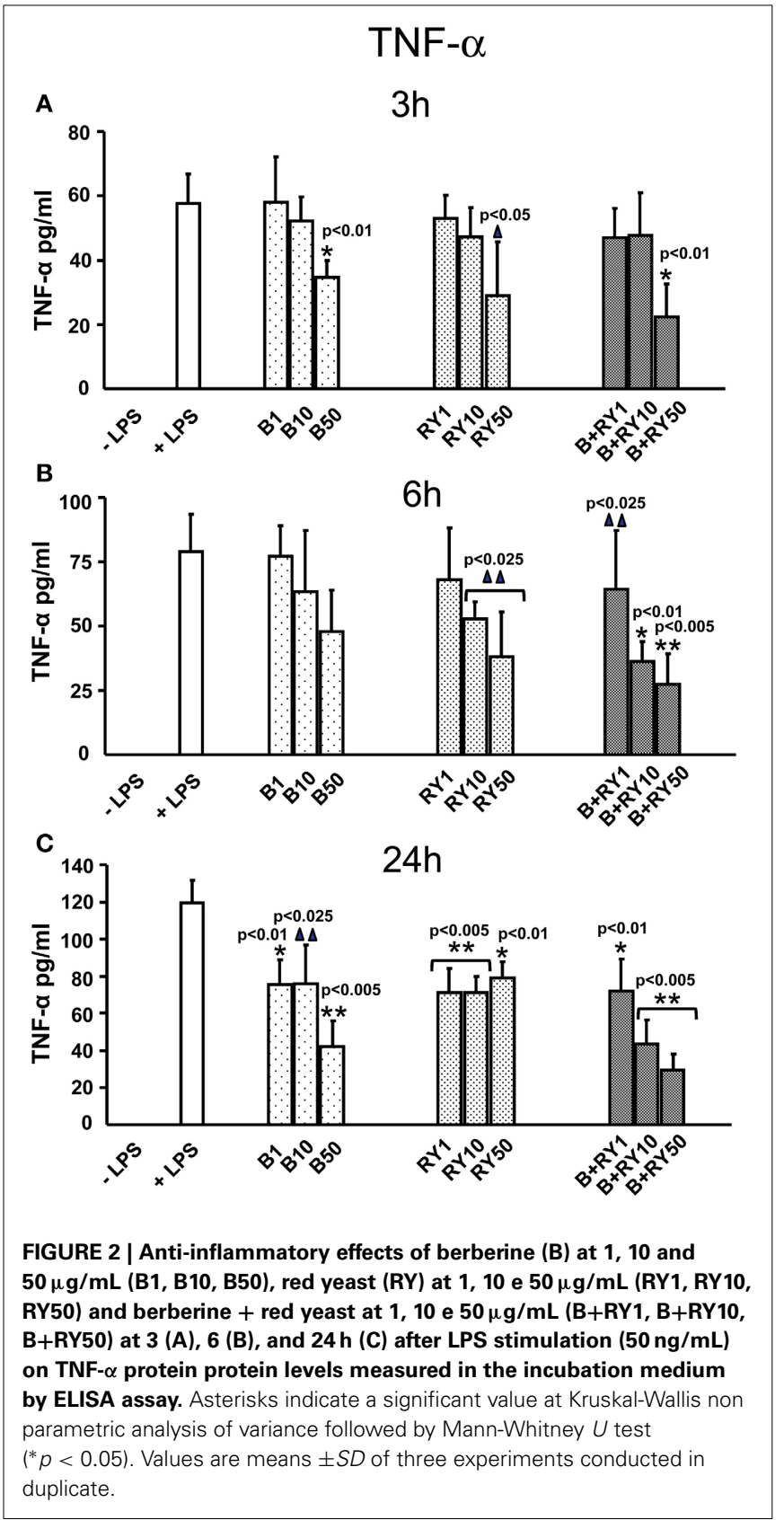

yeast concomitant treatment at $3 \mathrm{~h}(p<0.05)$, but not at 6 and $24 \mathrm{~h}$ (Figures 4A-C).

\section{DISCUSSION}

It has been previously demonstrated that mononuclear cells MNCs in obese subjects are involved in proinflammatory state with increased formation of proinflammatory transcriptional intranuclear factor $\mathrm{kB}(\mathrm{NF}-\mathrm{kB})$ and proinflammatory genes regulated by NF-kB (Ghanim et al., 2004). Berberine antiinflammatory effects have been largely demonstrated both in animal models and in other experimental systems (Ivanovska and Philipov, 1996). In addition, experimental evidence indicate a decrease of mRNA levels of inflammation marker (TNF- $\alpha$, IL-6 


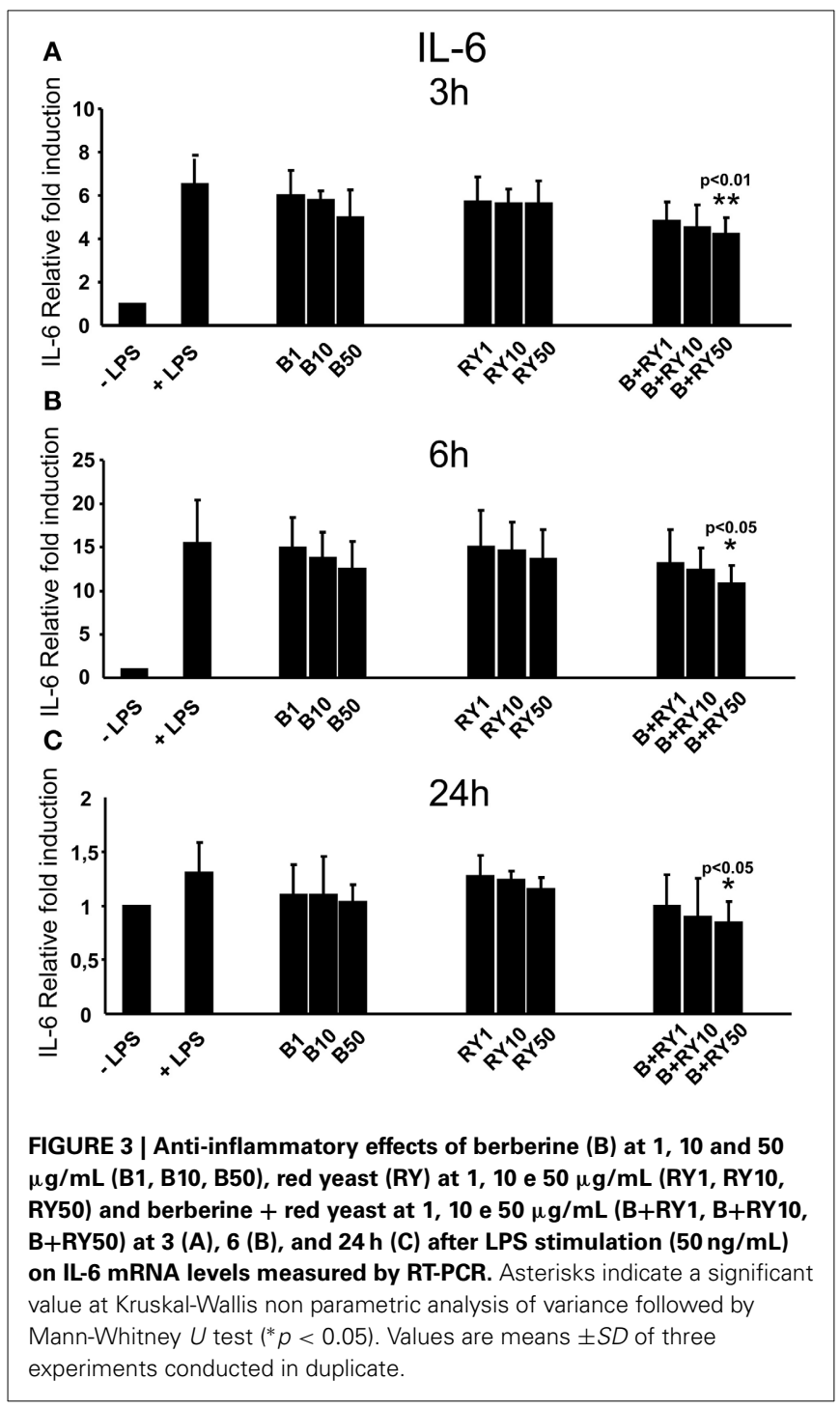

and CRP) in berberine-treated immortalized 3T3-L1 adipocytes (Choi et al., 2006). In the last years, moreover, different studies have demonstrated red yeast anti-inflammatory effects (Chen et al., 2008; Lin et al., 2008b).

The results of our study show that both berberine and red yeast carried out anti-inflammatory action through an inhibition of proinflammatory cytokines, IL- 6 and TNF- $\alpha$ release and their gene expression in PBMCs activated by LPS. It is worth noting that berberine and red yeast were active in a synergistic way; we observed that IL-6 secretion inhibition in berberine plus red yeast stimulated PBMCs cells was more evident at low concentration $(1 \mu \mathrm{g} / \mathrm{mL})$ and at short time $(3 \mathrm{~h})(65.2 \%)$. In the same conditions, berberine or red yeast alone inhibited IL- 6 secretion by $33 \%$ and $3 \%$, respectively. Synergistic effect of berberine and red yeast was also evident in TNF- $\alpha$ secretion inhibition; in this case this synergism appreciated during entire time-course $(3,6$ e $24 \mathrm{~h})$, but at high concentration $(50 \mu \mathrm{g} / \mathrm{mL})$. Berberine plus red yeast were effective in a synergistic way also during cytokines transcription or post-transcription events regulating mRNA levels. It

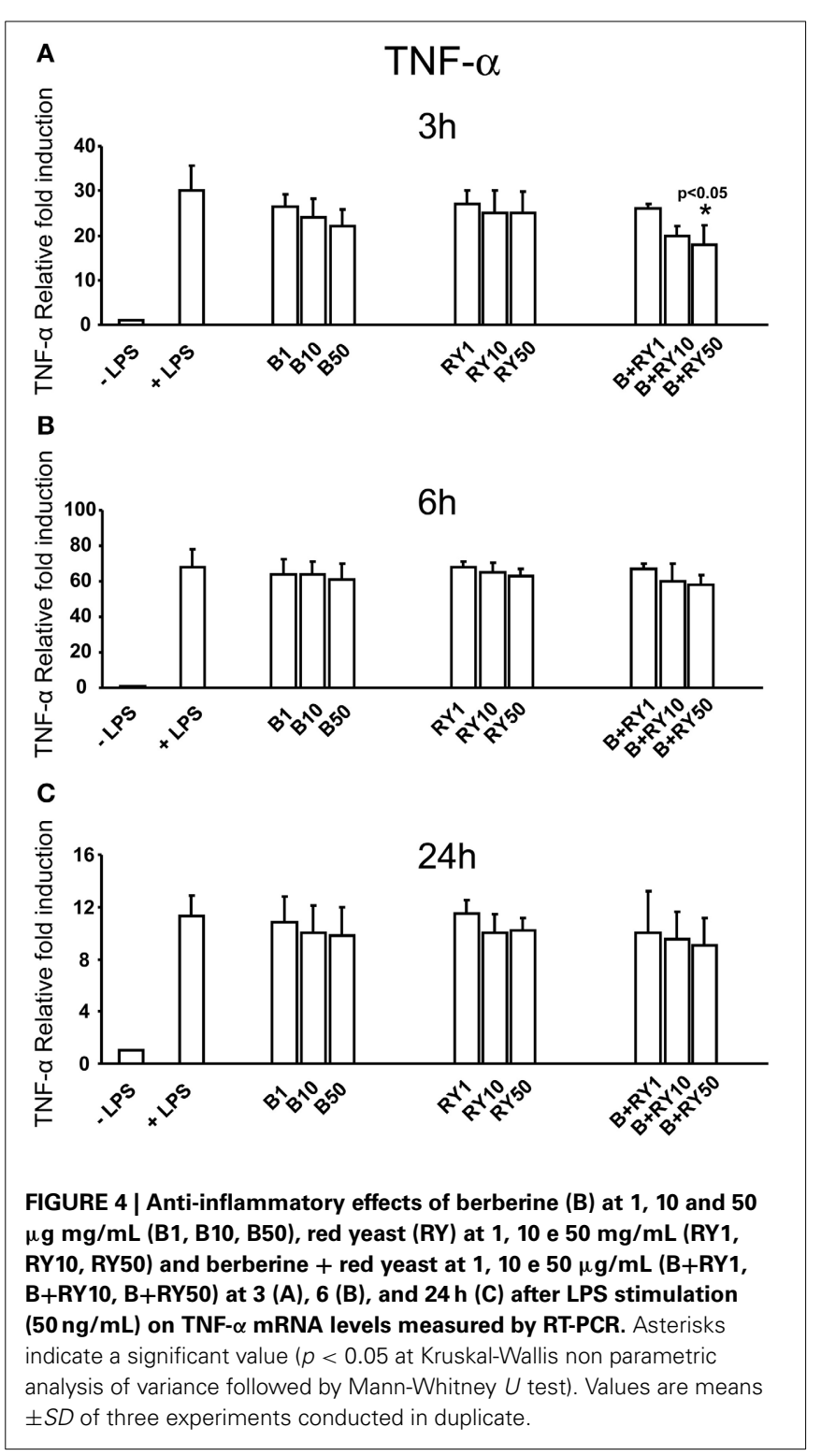

is evident from our data that, except for the combination of both compounds, there is no effect of both substances administered alone on mRNA levels of TNF- $\alpha$ or IL- 6 . Nevertheless, this suggest that both substances carried out an effect at post-transcriptional level even if this hypothesis needs further investigation.

Recent studies have shown berberine protective effect in the treatment of metabolic disorders such as body weight reduction, cholesterol, and glycemia level reduction (Lee et al., 2006; Yin et al., 2008; Affuso et al., 2010). In addition, several studies attribute to berberine an anti-obesity effect, because it is able to inhibit adipogenesis (Choi et al., 2006; Huang et al., 2006; Kim et al., 2007; Yi et al., 2008; Hu and Davies, 2010). It has been reported that monacolin $\mathrm{K}$ is a red yeast metabolically active compound effective in plasma lipid lowering (Cicero et al., 2010). According to previous data (Bastard et al., 2000; Juge-Aubry et al., 2004; Aygun et al., 2005; Park et al., 2005), our results indicate that the induction of proinflammatory cytokines, IL- 6 and 
TNF- $\alpha$ production, caused in PBMs stimulated by LPS, is similar to that observed in obese subject, where metabolic disorders, proinflammatory state and insulin resistance are often associated. Therefore, our study suggests that berberine and red yeast could represent a useful pharmacological approach to reduce proinflammatory status associated with these pathologies.

\section{SUPPLEMENTARY MATERIAL}

The Supplementary Material for this article can be found online at: http://www.frontiersin.org/journal/10.3389/fphar. 2014.00230/abstract

\section{REFERENCES}

Affuso, F., Ruvolo, A., Micillo, F., Sacca, L., and Fazio, S. (2010). Effect of a nutraceutical combination (berberine, red yeast rice and policosanols) on lipid levels and endothelial function randomized, double-blind, placebo-controlled study. Nutr. Metab. Cardiovasc. Dis. 20, 656-661. doi: 10.1016/j.numecd.2009.05.017

Aygun, A. D., Gungor, S., Ustundag, B., Gurgoze, M. K., and Sen, Y. (2005). Proinflammatory cytokines and leptin are increased in serum of prepubertal obese children. Mediat. Inflamm. 2005, 180-183. doi: 10.1155/MI.2005.180

Bastard, J. P., Jardel, C., Bruckert, E., Blondy, P., Capeau, J., Laville, M., et al. (2000). Elevated levels of interleukin 6 are reduced in serum and subcutaneous adipose tissue of obese women after weight loss. J. Clin. Endocrinol. Metab. 85, 3338-3342. doi: 10.1210/jc.85.9.3338

Bastard, J. P., Maachi, M., Lagathu, C., Kim, M. J., Caron, M., Vidal, H., et al. (2006). Recent advances in the relationship between obesity, inflammation, and insulin resistence. Eur. Cytokine Netw. 17, 4-12.

Chen, W. P., Ho, B. Y., Lee, C. H., and Pan, T. M. (2008). Red mold rice prevents the development of obesity, dyslipidemia and hiperinsulinemia induced by high-fat diet. Int. J. Obes. 32, 1694-1704. doi: 10.1038/ijo.2008.156

Choi, B. H., Ahn, I. S., Kim, Y. H., Park, J. W., Lee, S. Y., Hyun, C. K., et al. (2006). Berberine reduces the expression of adipogenic enzymes and inflammatory molecules of 3T3-L1 adipocytes. Exp. Mol. Med. 38, 599-605. doi: 10.1038/emm.2006.71

Cicero, A. F. G., Benvenuti, C., and ARMoweb study Group. (2010). Efficacy of a red yeast rice based nutraceutical in large subgroups of hypercholesterolemic subjects in every day clinical practice. Mediterr. J. Nutr. Metabol. 3, 239-246. doi: 10.1007/s12349-010-0028-5

Doyle, A., and Griffiths, J. B. (eds.). (1998). "Cell quantification," in Cell and Tissue Culture Laboratory Procedures in Biotechnology (Chichester: John Wiley \& Sons Inc), 76-81.

Ghanim, H., Aljada, A., Hofmeier, D., Syed, T., Mohanty, P., and Dandona, P. (2004). Circulating monocellular cells in the obese are in a proinflammatory state. Circulation 110, 1564-1571. doi: 10.1161/01.CIR.0000142055. 53122.FA

Hu, Y., and Davies, G. E. (2010). Berberine inhibits adipogenesis in high-fat dietinduced obesity mice. Fitoterapia 81 , 358-366. doi: 10.1016/j.fitote.2009.10.010

Huang, C., Zhang, Y., Gong, Z., Sheng, X., Li, Z., Zhang, W., et al. (2006). Berberine inhibits 3T3-L1 adipocyte differentiation thorough PPAR $\gamma$ pathway. Biochem. Biophys. Res. Commun. 348, 571-578. doi: 10.1016/j.bbrc.2006.07.095

Ivanovska, N., and Philipov, S. (1996). Study on the anti-inflammatory action of Berberis Vulgaris root extract, alkaloid fractions and pure alkaloids. Int. J. Immunopharmacol. 18, 553-561. doi: 10.1016/S0192-0561(96)00047-1
Juge-Aubry, C. E., Somm, E., Chicheportiche, R., Burger, D., Pernin, A., CuénodPittet, B., et al. (2004). Regulatory effects of interleukin (IL)-1, interferon-beta, and IL-4 on the production of IL-1 receptor antagonist by human adipose tissue. J. Clin. Endocrinol. Metab. 89, 2652-2658. doi: 10.1210/jc.2003-031219

Kim, S. H., Shin, E. J., Kim, E. D., Bayaara, T., Frost, S. C., and Hyun, C. K. (2007). Berberine activates GLUT1-mediated glucose uptake in 3T3-L1 adipocytes. Biol. Pharm. Bull. 30, 2120-2125. doi: 10.1248/bpb.30.2120

Lee, Y. S., Kim, W. S., Kim, K. H., Yoon, M. J., Cho, H. J., Shen, Y., et al. (2006) Berberine, a natural plant product, activates AMP-activated protein kinase with beneficial metabolic effects in diabetic and insulin resistant state. Diabetes 55 , 2256-2264. doi: 10.2337/db06-0006

Lin, C. P., Chen, Y. H., Chen, J. W., Leu, H. B., Liu, T. Z., Liu, P. L., et al. (2008b). Cholestin (Monascus purpureus rice) inihibits homocysteine-induced reactive oxygen specis generation, NFkB activation, and vascular cell adhesion molecule1 expression in human aortic endothelial cells. J. Biomed. Sci. 15, 183-196. doi: 10.1007/s11373-007-9212-0

Lin, Y. L., Wang, T. H., Lee, M. H., and Su, N. W. (2008a). Biologically active components and nutraceticals in the Monascus-fermented rice: a review. Appl. Microbiol. Biotechnol. 77, 965-973. doi: 10.1007/s00253-007-1256-6

Park, H. S., Park, J. Y., and Yu, R. (2005). Relationship of obesity and visceral adiposity with serum concentrations of CRP, TNF-alpha and IL-6. Diabetes Res. Clin. Pract. 69, 29-35. doi: 10.1016/j.diabres.2004.11.007

Rickham, P. P. (1966). Human experimentations. Code of ethics of the world medical association. declaration of Helsinki. Br. Med. J. 65, 367-368.

Solá, E., Jover, A., López-Ruiz, A., Jarabo, M., Vayá, A., Morillas, C., et al. (2009). Parameters of inflammation in morbid obesity: lack of effect of moderate weight loss. Obes. Surg. 19, 571-576. doi: 10.1007/s11695-008-9772-8

Weisberg, S. P., McCann, D., Desai, M., Rosenbaum, M., Leibel, R. L., and Ferrante, A. W. (2003). Obesity is associated with macrophage accumulation in adipose tissue. J. Clin. Invest. 112, 1796-1808. doi: 10.1172/JCI200319246

Yi, P., Lu, F. E., Xu, L. J., Chen, J., Dong, H., and Wang, K. F. (2008). Berberine reverses free-fatty-acid-induced insulin resistence in 3T3-L1 adipocytes through targeting IKK $\beta$. World J. Gastroenterol. 14, 876-883. doi: 10.3748/wjg.14.876

Yin, J., Gao, Z., Liu, D., Liu, Z., and Ye, J. (2008). Berberine improves glucose metabolism through induction of glycolysis. Am. J. Physiol. Endocrinol. Metab. 294, E148-E156. doi: 10.1152/ajpendo.00211.2007

Conflict of Interest Statement: The authors declare that the research was conducted in the absence of any commercial or financial relationships that could be construed as a potential conflict of interest.

Received: 24 March 2014; accepted: 29 September 2014; published online: 20 October 2014.

Citation: Spatuzza C, Postiglione L, Covelli B, Ricciardone M, Benvenuti C, Mondola $P$ and Belfiore $A$ (2014) Effects of berberine and red yeast on proinflammatory cytokines IL-6 and TNF- $\alpha$ in peripheral blood mononuclear cells (PBMCs) of human subjects. Front. Pharmacol. 5:230. doi: 10.3389/fphar.2014.00230

This article was submitted to Inflammation Pharmacology, a section of the journal Frontiers in Pharmacology.

Copyright (C) 2014 Spatuzza, Postiglione, Covelli, Ricciardone, Benvenuti, Mondola and Belfiore. This is an open-access article distributed under the terms of the Creative Commons Attribution License (CC BY). The use, distribution or reproduction in other forums is permitted, provided the original author(s) or licensor are credited and that the original publication in this journal is cited, in accordance with accepted academic practice. No use, distribution or reproduction is permitted which does not comply with these terms. 